\title{
"Música em PAS": a música como objeto de avaliação do Programa de Avaliação Seriada da Universidade de Brasília (PAS/UnB)
}

Maria Cristina de Carvalho Cascelli de Azevedo*

\section{Resumo}

Este artigo discute a proposta da música para o Programa de Avaliação Seriada da Universidade de Brasília (PAS/UnB), tendo como referência a participação da autora nos grupos de sistematização, elaboração e revisão dos programas de 2001 e 2006, bem como atividades de pesquisa e de prática docente relacionadas com o PAS. O texto apresenta o programa, sua concepção de avaliação e os princípios e pressupostos pedagógico-musicais que orientam a inserção do conhecimento musical como objeto de avaliação obrigatório nesse tipo de concurso. Para isso, adotamos como referência a versão de 2006 do PAS/UnB, resultado da $2^{\underline{a}}$ revisão do programa e vigente em 2011. O programa adota uma Matriz de Avaliação que integra competências, habilidades e objetos de conhecimento. O desenvolvimento de competências e habilidades na Música é orientado por um repertório musical que delimita o conteúdo e possibilita a realização de práticas e experiências musicais por meio de atividades de produção musical (execução, improvisação e composição musical), recepção (apreciação musical) e contextualização. Nesse processo, cabe às escolas e aos professores de música criar situações de ensino e aprendizagem musical em que a experiência musical seja celebrada no sentido de permitir a aprendizagem significativa e favorecer o sucesso dos alunos nas provas do PAS/UnB.

Palavras-chave: Programa de Avaliação Seriada, Ensino Médio, música na escola.

\section{"Música em PAS": music as an evaluation object of the program of serial university entrance examination of University of Brasília (PAS/ UnB)}

\section{Abstract}

This paper discusses the musical proposal to Program of Serial University Entrance Examination of University of Brasília (PAS/UnB). The discussion is based on author's participation on elaboration, systematization, and review groups of 2001 and 2006 programs, as well her researches and her teacher training activities with PAS. The text presents the program, its evaluation conception and the music-pedagogical principles and purposes that guide the insertion of musical knowledge as compulsory evaluation's object in the university entrance

\footnotetext{
* Doutora em Música/Educação Musical - Universidade de Brasília (UnB). Brasília, Distrito Federal.
} 


\section{Maria Cristina de Carvalho Cascelli de Azevedo}

examination. The last program's version has adopted an Evaluation's Matrix with some music competences, abilities and evaluation's objects. The development of music's competences and abilities is oriented by a music repertoire that defines the content and should be a way for development of musical practices and experiences (performance, improvisation and composition), reception (musical appraising) and context. In this process, the schools and its music teachers are responsible for create learning and teaching situations where the musical experience could be celebrated in sense of to promote a musical significant learning experience and the student's success in PAS/UnB exams.

Keywords: Program of Serial University Entrance Examination, Secondary School, Music in Schools.

\section{Introdução}

"Ridículo inserir música como matéria obrigatória! Nem todo mundo tem o mesmo talento e, por isso, elas deveriam escolher que artes querem ter. Fica muita matéria para estudar, sobrecarrega muito os alunos..." (aluno C11).

A inserção da música no PAS foi positiva pelo aspecto cultural, porém ainda seu efeito não pode ser percebido por causa do tempo e porque não é dada importância a essa disciplina, que tem um conteúdo extenso que nem sempre é bem explorado nas provas. (aluno C33) ${ }^{1}$

$\mathrm{Na}$ fala dos alunos de Ensino Médio, ambos da mesma turma e mesma escola, observamos percepções distintas e contraditórias com relação à aula de música e a inserção da Música como objeto de avaliação do Programa de Avaliação Seriada da Universidade de Brasília (PAS/UnB) e do vestibular ${ }^{2}$ da instituição. Nos discursos dos alunos, identificamos sua percepção e opinião sobre a inserção da música no PAS quanto: à sua obrigatoriedade; à natureza do conhecimento musical - dom ou cultura; ao acréscimo de conteúdos a serem apreendidos e avaliados para ingressar na universidade; ao valor que lhe é atribuído pelos alunos, pela escola e pelos elaboradores do PAS e das provas. As opiniões, embora ambíguas, refletem as reações e discussões que permeiam a inserção da música no PAS/UnB na comunidade educacional do Distrito Federal e entorno.

Neste artigo, nossa reflexão se volta para o seguinte questionamento: por que inserir música no PAS e no vestibular? Que princípios pedagógicos orientam essa inserção? Quais são as características do conteúdo musical nos subprogramas e nas provas? Que concepção de aula de música emerge do PAS? Assim, partimos da polêmica levantada para apresentar o programa, sua concepção de avaliação e os princípios e pressupostos pedagógico-musicais que orientam a inserção do conhecimento musical como objeto de avaliação 
obrigatório nesse tipo de concurso. Para isso, adotamos como referência a versão de 2006 do PAS/UnB, resultado da $2^{\text {a }}$ revisão do programa e vigente em 2011.

As reflexões apresentadas são consideradas relevantes, principalmente, diante do desafio de inserir a música como conteúdo curricular na Educação Básica. ${ }^{3} \mathrm{O}$ fato do ensino de música não estar ainda consolidado no sistema educacional brasileiro tem contribuído para a falta de conhecimento e compreensão dos pressupostos pedagógico-musicais da música no PAS, do seu repertório musical e das suas possibilidades didáticas para a aula de música no Ensino Médio. Além disso, discutir o PAS implica compreender que a música é um conhecimento que apresenta dimensões e conteúdos objetivos que podem ser identificados e avaliados (HENTSCHKE; DEL BEN, 2003). Portanto, este texto, além de divulgar a proposta da música no PAS, pretende contribuir com as discussões sobre a inserção da música na Educação Básica e como objeto de avaliação em programas de avaliação para ingresso nos cursos superiores.

\section{O PAS e a música no PAS}

O Programa de Avaliação Seriada da Universidade de Brasília (PAS/ UnB) seleciona os ingressantes aos cursos de graduação da universidade em três etapas equivalentes aos três anos do Ensino Médio. A avaliação é realizada ao término de cada série do Ensino Médio, que constituem etapas dos Subprogramas (triênios) do PAS, ou seja, cada Subprograma envolve três anos e é identificado pelo ano correspondente a primeira série. Por exemplo, os alunos que cursam a $1^{\underline{a}}$ série em 2011 participarão do triênio 2011-2013 que recebe a denominação Subprograma 2011-2013. Portanto, cada avaliação corresponde a uma etapa do respectivo Subprograma, em que a nota final representa a soma das notas das três etapas (CESPE, s/d).

O programa é inovador quanto aos seus pressupostos pedagógicos e formato de avaliação. Criado em 1995, ele representa o resultado de discussões sobre formas alternativas de ingresso na UnB iniciadas na década de 1980 e associadas à preocupação com a qualificação do Ensino Médio (BRASÍLIA, 2009). Segundo o Centro de Seleção e Promoção de Eventos (Cespe), o ConseIho Nacional da Educação (CNE), ao discutir as Diretrizes Curriculares Nacionais para o Ensino Médio, entende que, no que compete às universidades, são imprescindíveis dois tipos de articulações com o Ensino Médio: exames de ingresso ao Ensino Superior e formação de professores (BRASíLIA, 2009). O CNE entende que as Instituições de Ensino Superior (IES) têm um compromisso ético com os exames seletivos, seus conteúdos e competências:

O Ensino Superior está, assim, convocado a examinar sua missão e seus procedimentos de seleção, na perspectiva de um Ensino Médio que deverá ser mais unificado quanto às competências dos alunos e mais diversi- 


\title{
Maria Cristina de Carvalho Cascelli de Azevedo
}

\begin{abstract}
ficado quanto aos conhecimentos específicos que darão suporte à constituição dessas competências. E deverão fazê-lo com a ética de quem reconhece o poder que as exigências para ingresso no Ensino Superior exercem, e continuarão exercendo, sobre a prática curricular e pedagógica das escolas médias. (BRASIL, 1998, p. 99)
\end{abstract}

No que compete à UnB, o PAS incorpora essas metas aos seus objetivos avaliativos, procurando aprimorá-los no sentido de fomentar a integração entre a Universidade e o Ensino Médio e Fundamental, reconhecendo a influência dos exames na prática educativa das escolas. Nesse sentido, desde o início, a elaboração e a implantação do PAS foram efetivadas a partir do trabalho de Comitês ad hoc específicos formados por representantes de diferentes segmentos educacionais do Distrito Federal (Universidade, Secretaria de Estado de Educação do DF - SEDF, diretores, coordenadores e professores de escolas públicas e privadas). Dentre as inovações do programa destacam-se: 1) a inclusão das Artes (Música, Teatro e Artes Visuais) no programa, favorecendo a dimensão humanista do exame seletivo; 2) o compromisso do vestibular da instituição assumir gradativamente, a cada triênio, as alterações propostas pelo PAS (BRASÍLIA, s/d) e 3) ações de formação e interação com o Ensino Médio e Fundamental.

Com relação à inclusão das Artes no programa, esta foi sendo gradativamente alterada nas revisões trienais do PAS (MONTANDON; AZEVEDO; SILVA, 2011). O PAS - 1a geração (1996) definiu os objetos de avaliação do programa. Com relação às Artes, na prova, o candidato podia escolher uma entre as três linguagens artísticas. Nessa versão, o conteúdo era centrado na escrita e leitura musical e em conhecimentos de história da música ocidental e da música popular do Brasil (MONTANDON; AZEVEDO; SILVA, 2007).

A $2^{a}$ geração do PAS (2001), 1a revisão, adotou o conceito de competências e habilidades em detrimento da avaliação centrada na memorização e conteúdos. A proposta recebeu o nome de PAS: Objetos de Avaliação e foi organizada por eixos, focos, competência, objetos de conhecimentos e habilidades. O programa manteve a opção do candidato por uma das três linguagens artísticas, mas o conteúdo e a avaliação em Artes foram discutidos e alterados. Na Música, essa versão definiu os pressupostos pedagógico-musicais que orientariam o conhecimento musical a ser exigido no PAS, e que são mantidos ainda hoje: 1) conhecer os elementos musicais que constituem as diferentes músicas; 2) observar quanto e como esses elementos são trabalhados em diferentes músicas e 3) relacionar as músicas com o seu contexto sociocultural (MONTANDON; AZEVEDO; SILVA, 2007). Ainda segundo Montandon, Azevedo e Silva (2007), os elaboradores da proposta defendiam que os itens de música deveriam abordar questões de música e não sobre música. Isso implicaria uma prova auditiva em que as respostas se baseassem na audição de trechos musicais e não em comandos escritos. A impossibilidade de efetivar esse tipo de 
avaliação determinou a seleção de um repertório musical diversificado que contemplasse músicas ditas eruditas e populares de diferentes épocas e gêneros, música étnicas e regionais, músicas com diferentes fins e usos e música da mídia. A intenção foi elaborar questões e itens avaliativos que verificassem competências e habilidades associadas à apreciação prévia das obras musicais. $O$ repertório musical era escolhido e divulgado anualmente em cada etapa dos Subprogramas.

A proposta de avaliação atual, PAS $3^{\text {a }}$ geração 2006 , resultado da $2^{a}$ revisão iniciada em 2004, intensificou os princípios de interdisciplinaridade, contextualização e avaliação por competências e habilidades da prova. ${ }^{4}$ Dentre suas inovações se destacam: 1) a elaboração da Matriz de Objetos de Avaliação (Anexo $A$ ) que engloba três eixos complementares: eixo de competências, eixo de habilidades e eixo de objetos de conhecimento; 2) a inclusão das três linguagens artísticas - Música, Visuais e Cênicas -, sem opção e com abordagem interdisciplinar entre si e com as demais áreas do conhecimento; 3 ) a introdução da prova temática; 4) a formulação de itens dos tipos A (certo ou errado), B (resposta numérica), C (múltipla escolha) e D (resposta aberta elaborada pelo aluno) e 4) a inclusão de Filosofia e Sociologia como objetos de avaliação interdisciplinar (BRASÍLIA, 2011). A concepção interdisciplinar da prova exigiu ainda a redação de um texto interdisciplinar baseado nos objetos de conhecimentos a serem avaliados e a seleção de obras para apreciação prévia em Literatura, Música, Visuais, Cênicas, Sociologia e Filosofia. As obras são selecionadas por uma Comissão Especial de Acompanhamento do PAS com a participação da comunidade que decide o repertório de livros, filmes, músicas e obras de artes visuais (pintura, escultura, arquitetura, filmes e design) em plenárias públicas.

Com relação à incorporação das propostas do PAS no vestibular da UnB, os pressupostos avaliativos do PAS têm sido adotados, com algumas modificações, pelo vestibular a cada triênio, coincidindo com as revisões do PAS. Em 2009, por exemplo, o vestibular incorporou a Matriz de Objetos de Avaliação, o formato de itens interdisciplinares e a inclusão das Artes, da Sociologia e da Filosofia. Segundo histórico do CESPE (2009), o vestibular não adota o texto interdisciplinar dos Subprogramas do PAS e nem a relação de obras, mas seu conteúdo é consoante com as OCNEM e as respectivas Orientações Educacionais Complementares aos PCN (PCN+).

No que compete às ações de formação e interação com o Ensino Médio e Fundamental, o programa é organizado por subcoordenações e comissões especiais para desenvolvimento e acompanhamento do PAS. Nessa organização, destaca-se a Gerência de Interação Educacional ${ }^{5}$ (GIE) ou simplesmente Interação, responsável por uma rede de ações junto às escolas do Ensino Médio. A GIE realiza cursos para professores e desenvolve estudos que discutem o programa e suas revisões e atualizações (BRASíLIA, 2011). Para efetivar essas ações, a GIE administra o Fórum Permanente de Professores, o 


\section{Maria Cristina de Carvalho Cascelli de Azevedo}

Fórum de Alunos, o Fórum de Pais e a Comissão Especial de Acompanhamento do PAS. ${ }^{6}$ Esta última é formada por representantes da UnB, da SEDF e de representantes de instituições de Ensino Médio do DF que se reúnem regularmente para discutir o programa, redigir o texto dos Subprogramas e selecionar as obras para apreciação prévia.

No tópico seguinte, abordamos a concepção de avaliação musical e os pressupostos pedagógico-musicais que orientam a proposta da Música na $3^{\text {a }}$ geração do PAS - 2006.

\section{A Música no PAS 2006 - estrutura e princípios pedagógico-musicais}

Com relação à inserção da Música no PAS/UnB, observamos: 1) o amadurecimento da proposta da área e a sua gradativa aceitação e adesão pelas escolas do DF, principalmente privadas; 2) a valorização gradativa do conteúdo da Música no currículo das escolas e 3) a ampliação gradativa do mercado de trabalho para os professores de música. Como todo processo seletivo, a Música no PAS tem suscitado discussões sobre que conhecimento musical deve ser avaliado, por que e para quê. Contudo, ainda não temos uma avaliação sistemática do impacto da inserção da música no PAS/UnB. Até o momento, nosso olhar tem sido direcionado para uma análise dos Subprogramas e das provas da $2^{\underline{a}}$ revisão do PAS/UnB, período 2006-2011, que tem fornecido subsídios para compreendermos esse processo. Assim, neste tópico, apresentamos de forma mais detalhada a estrutura do programa sob o ponto de vista da Música e alguns dados de pesquisas realizadas nos documentos dos PAS (programas e provas) e com alunos e professores do Ensino Médio.

A estrutura do PAS/UnB - a Música na matriz de objetos de avaliação, nos objetos de conhecimento e nas provas

Como já explicitado, o PAS/UnB reconhece sua influência no Ensino Médio e na prática docente. Na Música, essa influência é observada, principalmente, na inserção de aula de Música em escolas particulares de Brasília, em cursos preparatórios para o PAS e na prática educativa dos professores (VAZ; AZEVEDO, 2010). Em entrevista com professores de Música do Ensino Médio, Vaz e Azevedo (2010) destacam a importância do repertório musical, do texto dos subprogramas e das provas na elaboração e condução das aulas de Música. Para compreensão de como esses documentos influenciam a prática educativa desses professores, relatamos, neste tópico, a estrutura da Matriz de Objetos de Avaliação, dos textos dos Subprogramas que acompanham a Matriz e das provas. No decorrer da descrição desses documentos, destacamos trechos e itens que abordam a Música como objeto de avaliação.

A Matriz de Objetos de Avaliação é a essência da concepção de avaliação do PAS. Nela, como já dito, são apresentadas as competências e habilidades a serem avaliadas (Anexo A). A Matriz é representada na forma de tabela 
em que o eixo vertical elenca cinco competências ${ }^{7}$ e o eixo horizontal 12 habilidades $^{8}$ distribuídas em quatro grandes operações cognitivas: interpretar, planejar, executar, criticar. Nas competências, observa-se que saber o que é ou o saber sobre não é suficiente (SWANWICK, 2003). É importante também compreender como esse saber se insere no mundo e é significado por ele e também saber ser e saber tomar decisões, o que implica valores, ética, autonomia e cidadania. As habilidades cognitivas, associadas às competências, reforçam a intenção não conteudista do programa (Anexo $A)$. Com relação à Música, os estudos e pesquisas realizados indicam que as competências 1 (C1) e 2 (C2) são as mais exploradas nas avaliações do PAS (VAZ; AZEVEDO, 2010). A Competência 1 relaciona-se com a interpretação e compreensão da linguagem musical, ou seja, conhecer os elementos musicais que constituem as diferentes músicas, como eles estão organizados e o quanto esses elementos estão presentes em cada música. Na Competência 2 é avaliada a compreensão do contexto histórico e social em que as músicas se inserem e os significados que o homem atribui às diferentes manifestações musicais (GREEN, 1997; 2002). Apesar de não serem identificadas com frequência nas provas analisadas, as demais competências também podem ser observadas e avaliadas mediante proposições de apreciação musical (BRASIL, 2002; 2006). Contudo, em sala de aula, o conjunto de competências expresso nas diretrizes curriculares pode ser trabalhado e avaliado em diferentes situações de ensino e aprendizagem musical que envolve ouvir, tocar, criar, refletir e contextualizar.

Os Objetos de Conhecimentos (OC) representam a $3^{\text {a }}$ dimensão da Matriz. Eles são temáticas transversais às competências e habilidades e possibilitam a interdisciplinaridade entre diferentes áreas do conhecimento. Os OCs orientam os textos dos Subprogramas, nos quais são apresentados e desenvolvidos em forma de questionamentos e conteúdos interdisciplinares. No caso das obras selecionadas para cada etapa do PAS, os OCs explicitam seus conteúdos e conhecimentos, sugerindo possíveis relações de intedisciplinaridade e de contextualização. Cada Subprograma pode apresentar uma relação variável de 10 a 11 objetos de conhecimentos que constituem cada um, um capítulo a ser desenvolvido em cada Subprograma (Anexo A). Os Objetos de Conhecimentos relacionam-se entre si e apresentam natureza diferenciada, isto é, alguns abordam temas humanos, sociais e culturais enquanto outros tratam de temáticas relacionadas com a matéria e a natureza física. ${ }^{9} \mathrm{Em}$ cada um desses temas podem ser apresentadas cinco ou mais obras de cada linguagem artística.

Contudo, o texto dos OCs discute também conteúdos de forma interdisciplinar tratados por mais de uma área de conhecimento. Por exemplo, no Subprograma da $2^{\text {a }}$ Etapa do Subprograma 2006 é sugerida uma relação entre matriz matemática e tablatura de violão. Segundo o texto, as linhas da matriz matemática podem também ser interpretadas como as cordas do instrumento e os números como as posições das notas em cada corda e casa do violão. O texto destaca o seguinte conteúdo: 


\title{
Maria Cristina de Carvalho Cascelli de Azevedo
}

\begin{abstract}
Na matriz, as linhas representam as cordas de um violão ou guitarra. Assim, a primeira linha de baixo representa a corda mais grossa (grave) e a de cima, a mais fina (aguda). Por sua vez, os números representam o traste em que a corda deve ser pressionada.

A idéia de matriz pode ser aplicada para compreender a construção de acordes e notas musicais na tablatura, representação gráfica muito comum na música popular. Por exemplo, na figura acima, os acordes de C, F e G7 representam, na tonalidade de Dó Maior, os graus I, IV e V7. (CESPE/UNB, 2009 - 2011)
\end{abstract}

O texto apresenta diferentes conhecimentos musicais (notas musicais no violão, encadeamento harmônico, noção de melodia e harmonia, por exemplo) e como representá-los, em que o código de representação gráficomusical pode também ser interpretado como uma matriz matemática. Nessa mesma linha de pensamento, o Subprograma propõe outras interações entre música e outros objetos de avaliação. É importante destacar que, embora o programa faça uma apresentação teórica e representacional do conhecimento musical, cabe ao professor em sala de aula relacionar o conhecimento teórico com a prática musical, procurando aproximar os alunos do fenômeno musical em si e sua compreensão musical.

Em outras situações, o Subprograma trata as obras musicais como um meio para desenvolvimento da interdisciplinaridade e contextualização para outras áreas do conhecimento. Na $3^{\underline{a}}$ etapa, por exemplo, as músicas Até quando esperar (Plebe Rude), Brasil com P (GOG), Beba Coca-Cola (Gilberto Mendes e Décio Pignatari) e Cidadão (Lúcio Barbosa) podem dialogar com a Sociologia e a Filosofia abordando questões raciais, éticas, morais, políticas e de desigualdade social:

\footnotetext{
Ironia, criticismo e valores éticos também estão presentes na canção Cidadão, de Lúcio Barbosa, com interpretação de Zé Ramalho, na música Até Quando Esperar, de André X, Gutje e Philippe Seabra, interpretada pelo grupo Plebe Rude e na composição vocal Motet em Ré m ou Beba Coca-Cola, de Gilberto Mendes e Décio Pignatari. Já o rapper GOG (Genival Oliveira Gonçalves) conclama o ouvinte a refletir sobre os problemas sociais e políticos do país no rap Brasil com P. (CESPE/ UnB, 2010)
}

No texto fica claro que a ênfase está na contextualização sociocultural das músicas, que pode ser compreendida pela sua situação histórica e temporal e pela mensagem transmitida pelas letras. A forma como o discurso musical é explorado em cada música, seus elementos musicais e sua estrutura podem ser abordados pelo professor na análise de como os elementos musicais reforçam e enfatizam as músicas. Pode-se dizer que esse tipo de conhecimentos é 
sobre música, mas não inviabiliza a possibilidade do conhecimento musical em si.

A diversidade de possibilidades de abordagem do conhecimento musical facilita a exploração das músicas em muitos objetos de conhecimento, entretanto, os OCs não são conteúdos programáticos, mas orientações sobre como o professor deve interpretar e desenvolver os conteúdos em sala de aula.

Quanto às provas do PAS, elas seguem modelo e estrutura elaboradas pelo CESPE, que pesquisa e desenvolve formatos de avaliação inovadores. De modo geral, as provas apresentam cerca de 120 itens distribuídos em duas partes: Parte I - Língua Estrangeira, com cerca de 10 itens para cada língua estrangeira Inglês, Espanhol ou Francês - e a Parte II, que corresponde à seção interdisciplinar: Português, História, Geografia, Filosofia, Sociologia, Redação, Matemática, Física, Química, Biologia, Artes Cênicas, Visuais e Música.

As questões das provas são dos tipos: A, B, C ou D como já dito, e variam de peso entre si: peso 1 para tipo $\mathbf{A}$; peso 2 para tipo $\mathbf{B}$ e $\mathbf{C}$ e peso 3 para tipo D. Além disso, cada etapa apresenta um peso diferenciado: peso 1 para a $1^{\underline{a}}$ etapa; peso 2 para a $2^{\underline{a}}$ etapa e peso 3 para a $3^{\underline{a}}$ etapa. As instruções do caderno de prova destacam o fato das questões do tipo A e C, quando assinaladas incorretamente, terem peso negativo (-1). Esse tipo de avaliação dificulta o "chute" do aluno, mas pune o erro duas vezes (CESPE/UnB, 2010). O Subprograma de 2011 apresenta as seguintes inovações: aumento do número de questões do tipo $D$, mínimo de 4 por etapa com objetivo de qualificar a redação dos alunos.

As características das provas do PAS, juntamente com os Subprogramas, estão direcionando o ensino e a aprendizagem da música no Ensino Médio em Brasília. Segundo Vaz e Azevedo (2010), os professores apresentam opiniões contraditórias sobre as provas, o repertório musical e os Subprogramas do PAS. De modo geral, eles sugerem que as provas e os Subprogramas apresentam aspectos positivos relacionados como o conhecimento musical que está sendo tratado e avaliado no PAS, mas também aspectos problemáticos relacionados com o repertório musical e como este é explorado no PAS. Eles reconhecem e destacam a importância da inserção da música no PAS para a formação cultural e estética dos jovens, mas consideram que as provas não refletem o valor e o conteúdo musical que os Subprogramas exigem. Para eles, as provas do PAS são mais fáceis do que as atividades de simulados elaboradas por eles. Na fala dos professores, percebemos que a forma como os Subprogramas são assimilados e compreendidos refletem no planejamento das aulas, o que influencia o rendimento do aluno nas provas.

Em geral, eles [os alunos] têm facilidade, eu acho que, no meu caso, as aulas são bem mais complexas que a prova, minhas questões também são bem mais exigentes e complexas do que a prova, então no final das con- 


\section{Maria Cristina de Carvalho Cascelli de Azevedo}

tas, quando eles fazem a prova, eles sempre acham bem mais fácil do que eles viram ao longo do ano. (E. CARLOS, p. 4)

A prova do PAS... [...] eu me recordo agora que o ano passado [2009], [...] eles fizeram o vestibular e me procuraram logo depois do vestibular falando "poxa, professora, caiu tudo que você falou", inclusive um aluno falou assim: "poxa, professora, foi você que elaborou a prova do PAS?" [...] mas isso é o costume já, da gente estar inteirado à prova, então eu leio muito, quando sai a prova eu vou junto, levo a prova pra dentro de sala, pra discutir com eles, o quê que caiu, como caiu. (E. VERA, p. 6)

A percepção dos professores entrevistados sobre as provas e 0 Subprograma do PAS está relacionada com a forma como eles compreendem a proposta de avaliação do programa, seus princípios e conteúdo na sua prática educativa. Esta, por sua vez, reflete suas concepções sobre a aula de música e sobre conhecimento musical. Essas concepções se manifestam também nas suas sugestões para o PAS.

Quanto ao conteúdo cobrado eu acho que a gente pode ampliar um pouquinho a questão da teoria musical [...], mas a gente não deve voltar a ter aula de teoria, mas... mais do que História da Música, está as notas, os acordes da estrutura da música. Permite a gente trabalhar com algumas práticas em sala, permite a escola como um todo valorizar mais a nossa matéria, ver a dificuldade dela, ao mesmo tempo o resultado que ela pode dar. [...]. E, claro, cabe aos examinadores e quem for criar o programa, sugerir possibilidades mais criativas de abordar teoria. Tá faltando isso... Já tem um pouquinho no segundo ano, mas tá faltando mais. (E.CARLOS, p. 5)

[...] quero que caia [nas provas] mais das obras de música mesmo, quero que continue e sempre aumentando nesse sentido. Porque agora [2010] no segundo ano, que são 20 músicas [no repertório]... Ano passado eles cobraram acho que quatro, sabe, foram poucas [questões], então assim, cobrem mesmo, porque os meninos..., eles têm que sentir essa importância da música. A música tem que fazer diferença [...]e a UnB fez muito isso, buscar a importância mesmo da música ligada às outras artes, da música inserida num contexto para o Ensino Médio. (E. VERA, p. 9)

Nas falas dos professores, percebemos a necessidade de valorização do que eles compreendem como sendo música e conhecimento musical. $\mathrm{O}$ professor Carlos destaca a importância da teoria e critica o foco histórico e sociológico que as questões de música têm apresentado. Para ele, o contexto não deve ser mais valorizado do que o conhecimento musical baseado nos 
materiais sonoros como acordes, nota, grafia musical. A concepção do professor sobre música e conhecimento musical está centrada no conhecimento dos materiais sonoros, o que Grossi (2003) considera conhecimento fragmentado que, muitas vezes, não contempla a forma como as pessoas percebem e interagem com o fenômeno musical. No entanto, vale destacar que o professor Carlos argumenta que o conhecimento teórico deve ser trabalhado no Subprograma e nas provas de forma "criativa" e interessante para o aluno. A professora Vera também argumenta em favor da inclusão de questões mais musicais nas provas. Para ela o repertório é pouco explorado nos itens avaliados.

Apesar de terem concepções diferentes sobre o que e como o conhecimento musical deve ser cobrado no PAS, os professores reconhecem a importância da inserção da música no PAS para o desenvolvimento cultural e humano dos jovens do Ensino Médio e destacam que essa inclusão tem propiciado a valorização da música como conhecimento e, consequentemente, o trabalho do professor de Música.

As opiniões dos professores reforçam a necessidade do PAS/UnB, por meio de seu Fórum de Professores, fomentar a interação entre universidade e PAS a fim de que ambos, elaboradores dos programas e professores nas escolas, possam aprimorar o programa e realmente desenvolver novas estratégias e metodologias de ensino de música no Ensino Médio.

\section{Algumas considerações finais}

A abordagem curricular por habilidades e competências extrapola a visão delimitada por conteúdos, favorecendo o diálogo com outras disciplinas e lembrando-nos que uma experiência musical não se limita à aquisição de conhecimentos para a prova do PAS, mas visa também a formação de cidadãos críticos e reflexivos. Além do desafio de dialogar com outras áreas, a preocupação do professor de música que trabalha com o PAS é manter o foco de suas aulas no conhecimento musical, enquanto propicia a contextualização e o diálogo da Música com outros saberes.

Apesar de a música exercer diversas funções,${ }^{10}$ nem sempre elas encorajam a construção e desenvolvimento de habilidades musicais. Tratar uma canção apenas pelo seu contexto histórico-social, explorando somente a letra, seria desconsiderar os aspectos intrínsecos que compõem a música e a experiência musical. A canção seria apenas um meio para abordar História ou análise textual. Por outro lado, identificar aspectos sonoros e musicais que representam ou contrastam com ideias do texto, analisar a forma como os materiais sonoros são tratados na canção, considerando o seu contexto composicional (época, estilo, função etc.) pode ser um exemplo de como trabalhar a apreciação musical. Nesse sentido, a canção é considerada objeto de conhecimento com seus elementos musicais e significados individuais e socioculturais. 
Entendemos que a música no PAS não precisa ser uma "sobrecarga" para o aluno, mas deve possibilitar a criação de pontes entre os saberes, competências e habilidades musicais dos alunos e os saberes, competências e habilidades a serem adquiridos para aprovação no exame seletivo. A aula de música no contexto do PAS deve promover o encontro entre o conhecimento musical intuitivo e o conhecimento sistematizado pelos objetos de avaliação do PAS. A natureza física, social, cultural, histórica e emocional da música favorece o diálogo com as demais áreas do conhecimento, possibilitando a interdisciplinaridade. Portanto, cabe às escolas e aos professores de música criar situações de ensino e aprendizagem musical em que a experiência musical seja significativa no sentido de permitir o desenvolvimento de saberes musicais e favorecer o sucesso dos alunos nas provas do PAS.

\section{Referências}

BRASIL. Ministério da Educação. Conselho Nacional da Educação. Diretrizes Curriculares Nacionais para o Ensino Médio. Parecer n. 15 da Câmara de Educação Básica do Conselho Nacional de Educação, Brasília, 1998.

. Ministério da Educação. Secretaria de Educação Básica. Parâmetros Curriculares Nacionais para o Ensino Médio. Brasília: Ministério da Educação, Secretaria de Educação Básica. Disponível em: http://portal.mec.gov.br/ seb/arquivos/pdf/14_24.pdf. Acesso em: 25 nov. 2011.

. Ministério da Educação. Secretaria de Educação Básica. Orientações Educacionais Complementares aos Parâmetros Curriculares Nacionais: Ensino Médio ( $\mathrm{PCN}+)$. Brasília: Ministério da Educação, Secretaria de Educação Básica, 2002. Disponível em: http://portal.mec.gov.br/seb/arquivos/pdf/ linguagens02.pdf. Acesso em: 25 nov. 2011.

. Ministério da Educação. Secretaria de Educação Básica. Orientações Curriculares Nacionais para o Ensino Médio. Brasília: Ministério da Educação, Secretaria de Educação Básica, 2006. Disponível em: http:// portal.mec.gov.br/seb/arquivos/pdf/book_volume_01_internet.pdf. Acesso em: 25 nov. 2011.

BRASÍLIA, Universidade de Brasília. Centro de Seleção e Promoção de Eventos (CESPE), Programa de Avaliação Seriada (PAS), Subprograma 2006 - 2a Etapa. Disponível em www.gie.cespe.unb.br. Acesso em: 07 de fev. 2008.

. CESPE. O que é o PAS. Disponível em: http://www.cespe.unb.br/pas/ oquepas/oquepas/oquepas.htm. Acesso em: 02 nov. 2011.

. CESPE. Vestibular da UnB: Na esteira da ousadia, liderando inovações. 2009. Disponível em: http://www.cespe.unb.br/vestibular/2VEST2011/ GuiaDoVestibulando/historia_recente_vestibular.pdf. Acesso em: 02 nov. 2011. 
BRASÍLIA, CESPE. PAS - 15 anos: programa em contínuo aperfeiçoamento, 2011. Disponível em: http://www.cespe.unb.br/pas/PAS_15\%20anos.pdf. Acesso em: 02 nov. 2011.

GREEN, L. Pesquisa em Sociologia da Educação Musical. Tradução Oscar Dourado. Revista da ABEM, n. 4, p. 25-35, 1997.

.How Popular Musicians Learn: a way ahead for music education. Hampshire: Ashgate Publishing Limited, 2002.

MONTANDON, I.; AZEVEDO, M.C.; SILVA, C. Música no Vestibular: O Programa de Avaliação Seriada de Brasília. In: OLIVEIRA, A.; CAJAZEIRA, R. (Orgs.). Educação Musical no Brasil. Capítulo 29, Salvador: P\&A, 2007, p. 207-213.

REIS; AZEVEDO. "Nós ouvimos a música de que gostamos ou aprendemos a gostar da que ouvimos?": A música em programas de avaliação seriada para alunos de Ensino Médio. In: CONGRESSO DAASSOCIAÇÃO NACIONAL DE PESQUISA E PÓS-GRADUAÇÃO EM MÚSICA, 18, 2008, Salvador. Anais.... Salvador: 2008.

O que Acontece com a Música da Escola? In: VIII ENCONTRO REGIONAL CENTRO-OESTE DAASSOCIAÇÃO BRASILEIRA DE EDUCAÇÃO MUSICAL (ABEM). Brasília, 2008b.

SWANWICK, K. Ensinando música musicalmente. Tradução de Alda Oliveira e Cristina Tourinho. São Paulo: Moderna, 2003.

IVAZ, F.; AZEVEDO, M. C. Música no PAS sob a perspectiva de análise dos programas e provas: $2^{a}$ etapa 2009 . Relatório de Iniciação Científica. Brasília: Impresso, 2010.

\footnotetext{
Notas

${ }_{1}$ As falas apresentadas na epígrafe fazem parte de pesquisa realizada com 84 alunos de 2 escolas públicas e 2 escolas privadas do Ensino Médio da Asa Norte de Brasília. A pesquisa teve por objetivo investigar que saberes e competências musicais estão sendo desenvolvidos na aula de música do Ensino Médio e sua relação com o repertório musical do PAS, a partir da ótica dos alunos.

2 Segundo o documento de criação do PAS/UnB, aprovado pelo Conselho de Ensino, Pesquisa e Extensão da UnB (CEPE/UnB), o vestibular da instituição deveria incorporar a cada 3 anos as inovações e mudanças desenvolvidas no Programa de Avaliação Seriada. Esse tipo de procedimento foi observado desde a criação do PAS em 1996, sendo que, em 2009, o vestibular da UnB adota as Artes como objeto de avaliação obrigatório e interdisciplinar em suas provas semestrais. Portanto, desde 2009 a Música tem sido objeto de avaliação do vestibular da instituição.

${ }^{3}$ Apesar da LDBEN n. 9394/96 ter incluído o ensino de Artes como componente curricular obrigatório nas escolas, o conteúdo musical não tem sido contemplado. A homologação da Lei n. 11769/2008 se propõe a corrigir esse equívoco e institui a obrigatoriedade do conteúdo musical na Educação Básica.
} 


\section{Maria Cristina de Carvalho Cascelli de Azevedo}

${ }^{4}$ Como ocorre no formato anterior, a $2^{\text {a }}$ revisão observa as orientações curriculares do Sistema Nacional do Ensino Médio, ou seja, as Diretrizes Curriculares para o Ensino Médio (DCNEM), os Parâmetros Curriculares Nacionais para o Ensino Médio (PCNEM), as Orientações Curriculares Nacionais (OCNEM) e as Orientações Curriculares Complementares aos PCN, conhecido por $\mathrm{PCN}+$.

${ }^{5}$ Informações disponíveis no site do CESPE/UnB http://www.cespe.unb.br/interacao/ infointeracao.htm\#informacoes. Acesso em: 01 out. 2011.

${ }^{6}$ A Comissão Especial de Acompanhamento do PAS foi criada em 17/02/1998 (CESPE/UnB, s/d).

${ }^{7}$ As competências podem ser resumidas em: C1 - domínio da linguagem; C2 - compreensão dos fenômenos, identificando articulações, interesses e valores envolvidos; C3 - tomada de decisões ao enfrentar problemas; C4 - construção de argumentação consistente e C5 - elaboração de propostas de intervenção na sociedade (Anexo A).

${ }^{8}$ As 12 habilidades são expressas em forma de objetivos e se relacionam com as competências do eixo vertical (Anexo A).

${ }^{9}$ Desde 2006, o subprogramas da 1ㄹ Etapa apresentam a seguinte relação de OCs: 1 - O ser humano como um ser no mundo; 2 - Indivíduo, cultura e identidade, 3 - Tipos e Gênero; 4 Estrutura; 5 - Energia, equilíbrio e movimento; 6 -Ambiente; 7 -A formação do mundo ocidental; 8 - Número, grandeza e forma; 9 - A construção do espaço; 10 - Materiais. Como OCs da $2^{\underline{a}}$ Etapa são definidos 10 temáticas: 1 - O ser humano como ser que pergunta e quer saber; 2 Indivíduo, cultura e mudança social; 3 - Tipos e gêneros; 4 - Estruturas; 5 - Energia e oscilações; 6 - Ambiente e vida; 7 - A formação do mundo ocidental contemporâneo; 8 - Número, grandeza e forma; 9 - A construção do espaço; 10 - Materiais.

${ }^{10}$ Segundo Merriam (1964 apud SWANWICK, 2003, p. 47), há várias funções para a música na sociedade. A saber: expressão emocional, prazer estético, diversão, comunicação, representação simbólica, resposta física, reforço da conformidade a normas sociais, validação de instituições sociais e rituais religiosos, contribuição para a continuidade e estabilidade da cultura e preservação da integração social.

\section{Correspondência}

Maria Cristina de Carvalho Cascelli de Azevedo - SHIS QI 23 conjunto 15 casa 05 Lago Sul, CEP 71660-150, Brasília, Distrito Federal.

E-mail: criscarvalhocazevedo@gmail.com

Recebido em 19 de novembro de 2011

Aprovado em 10 de dezembro de 2011 
"Música em PAS": a música como objeto de avaliação do Programa de Avaliação Seriada da Universidade de Brasília (PAS/U̧ßB)

\section{ANEXO A}

\section{MATRIZ DE OBJETOS DE AVALIAÇÃO DO PAS/UnB}

\begin{tabular}{|c|c|c|c|c|c|c|}
\hline \multirow{3}{*}{ 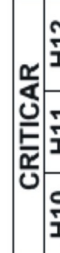 } & 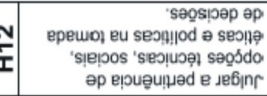 & & & & & \\
\hline & 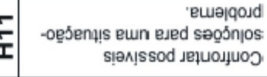 & & & & & \\
\hline & 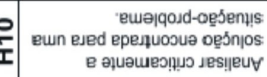 & & & & & \\
\hline \multirow{4}{*}{ 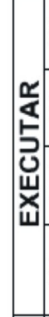 } & 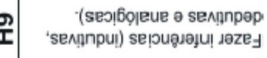 & & & & & \\
\hline & 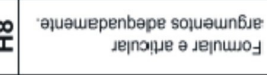 & & & & & \\
\hline & 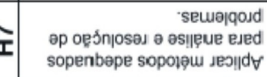 & & & & & \\
\hline & 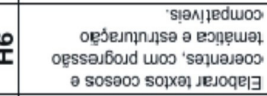 & & & & & \\
\hline \multirow{2}{*}{ 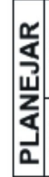 } & 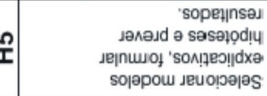 & & & & & \\
\hline & 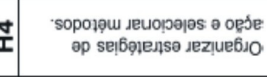 & & & & & \\
\hline \multirow{3}{*}{ 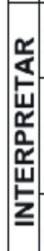 } & 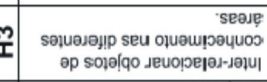 & & & & & \\
\hline & 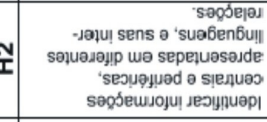 & & & & & \\
\hline & 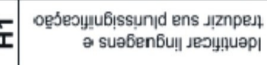 & & & & & \\
\hline & 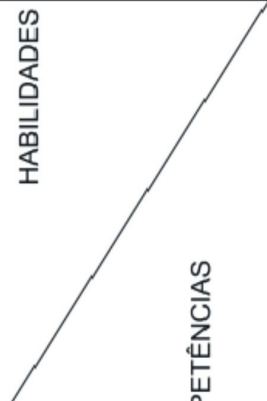 & 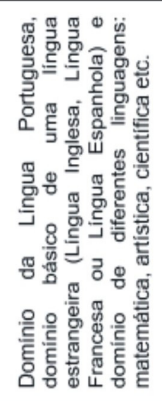 & 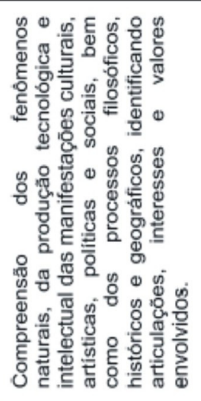 & 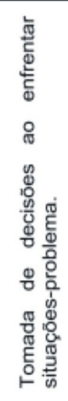 & 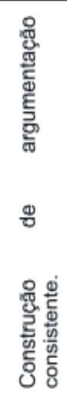 & 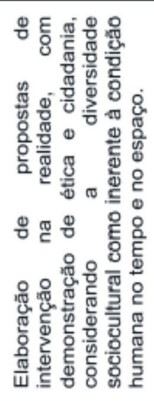 \\
\hline & ○ે & $\overline{0}$ & J & త్ & త & S \\
\hline
\end{tabular}


Maria Cristina de Carvalho Cascelli de Azevedo

\section{Objetos de Conhecimento}

(correspondestes ao símbolo

\section{Primeira Etapa}

1 - O ser humano como um ser no mundo

2 - Indivíduo, cultura e identidade

3 - Tipos e gêneros

4 - Estruturas

5 - Energia, equilíbrio e movimento

6 - Ambiente

7 - A formação do mundo ocidental

8 - Número, grandeza e forma

9 - A construção do espaço

10 - Materiais 